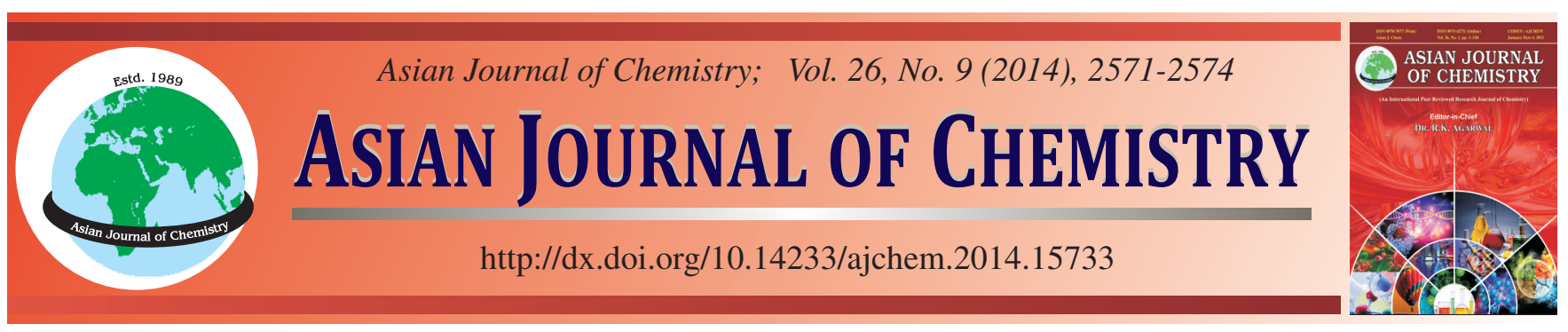

\title{
Novel Silica-Based Hybrid Adsorbents: Membrane Preparation and Copper(II) Adsorption Kinetics
}

\author{
Keyan Hu, Junsheng Liu* and Kechun Wang
}

Key Laboratory of Membrane Materials \& Processes, Department of Chemical and Materials Engineering, Hefei University, 99 Jinxiu Road, Hefei Economic and Technological Development Zone, Hefei 230601, P.R. China

*Corresponding author: Fax: +86 551 62158437; Tel: +86 551 62158439; E-mail: jsliu@hfuu.edu.cn

\begin{abstract}
A series of silica-based hybrid membranes were synthesized via sol-gel process. Thermogravimetric analysis was conducted to investigate their thermal stabilities. Adsorption experiment was performed to evaluate its adsorption performances for copper (II) removal. It is found that the temperature of thermal degradation could be arrived at near $230{ }^{\circ} \mathrm{C}$. The adsorption capacity of copper (II) on samples A-D increases with an increase in $\mathrm{N}$-[3-(trimethoxysilyl)propyl]ethylene diamine content, suggesting that the functionalized groups will play main effect on copper(II) adsorption. Moreover, based on the dependency of adsorption capacity on contact time, copper (II) adsorption kinetics was calculated to evaluate its adsorption properties. It is confirmed that the adsorption of copper(II) on sample D followed the Lagergren second-order model. This finding demonstrates that these hybrid membranes can be used as adsorbents to separate and recover copper(II) from copper (II)-containing water.
\end{abstract}

Keywords: Hybrid membrane, Adsorption, Kinetics, Copper(II)-bearing water.

\section{INTRODUCTION}

Water pollution caused by toxic heavy-metal ions, such as $\mathrm{Cu}^{2+}, \mathrm{Pb}^{2+}$, etc. has become a major environmental issue ${ }^{1-3}$. Typically, copper has been widely used in some industrial processes as electroplating, electrical industry as well as copper wares in everyday life. The amount of wastewater from industrial processes and the abandoned copper ware is thus increased and threatening the human health. As a result, the contamination from toxic copper(II)-bearing water has captured increasingly public attention. The removal of copper(II) from wastewater is thus significantly important and highly needed.

To eliminate or reduce copper(II) pollution, various effective treatment techniques are developed ${ }^{1-5}$. Among these, adsorption using functionalized hybrid materials has significant advantages over others because of its high efficiency, easy handling, availability of raw materials and cost effectiveness ${ }^{6}$. However, the use and recovery of these hybrid materials adsorbents in some continuous processes confronts some technical problems. To overcome the limitation of hybrid materials, membrane-type adsorbents will be more preferred.

Recently, a series of hybrid adsorbents are developed in our laboratory ${ }^{7-9}$. These hybrid adsorbents have revealed some excellent adsorption properties for heavy-metal ions in aqueous solution. Our continuing interest in these hybrid adsorbents stimulates us to do further work. Consequently, the objective of this work is to (1) develop a new membrane-type hybrid adsorbent, (2) evaluate its adsorption kinetics for copper(II) removal in aqueous solution as a model toxic heavy-metal.

\section{EXPERIMENTAL}

3-Glycidoxypropyltrimethoxysilane (GPTMS) and N-[3(trimethoxysilyl)propyl]ethylene diamine (TMSPEDA) was purchased from Silicone New Material Co. Ltd. of Wuhan University (China) and used without further purification. Poly(vinyl alcohol) (MW: 1750), N,N-dimethylformamide (DMF) and other reagents were of analytical grade and used as received.

Membrane preparation: The preparation of hybrid membranes (labeled as samples A-D) was conducted using GPTMS and TMSPEDA mixed solution as a hybrid precursor of sol-gel process. The procedure for the preparation of membrane can be described briefly as follows.

First, different amounts of GPTMS and TMSPEDA (the volume ratio of GPTMS and TMSPEDA was 1:4, 1:6, 1:8 and 1:10 for samples A, B, C and D, respectively) were dissolved in a DMF solution at room temperature and stirred for $3 \mathrm{~h}$ to synthesize the hybrid precursor. Second, the above-prepared hybrid precursor was added into 25 g $5 \%$ PVA aqueous solution and stirred violently for additional $3 \mathrm{~h}$. Subsequently, 
$0.2 \mathrm{~g}$ acetaldehyde was added into the mixed PVA solution to perform crosslinking reaction. The coating solution for membrane preparation was thus produced.

To obtain a hybrid membrane, the above-prepared coating solution was coated on a glass plate and aired for $24 \mathrm{~h}$ at room temperature. Subsequently, the membrane-type sample was dried at $70^{\circ} \mathrm{C}$ for $24 \mathrm{~h}$ in an oven. The hybrid membrane could thus be acquired.

Sample characterizations: Thermogravimetric analysis (TGA) thermal analysis of the above-prepared samples were measured using a Netzsch STA 409 PC/PG thermogravimetry analyzer, under a nitrogen flow using a heating rate of 20 $\left({ }^{\circ} \mathrm{C} \mathrm{min}^{-1}\right)$ from room temperature to $500{ }^{\circ} \mathrm{C}$.

Adsorption experiment: To examine the adsorption properties of these hybrid membranes for copper(II) in aqueous solution, adsorption experiment was conducted. The adsorption capacity $\left(\mathrm{q}_{\mathrm{Cu}^{2+}}\right)$ of copper(II) on these samples can be determined using eqn. 1 :

$$
\mathrm{q}_{\mathrm{Cu}^{2+}}=\frac{\left(\mathrm{C}_{0}-\mathrm{C}_{\mathrm{R}}\right) \mathrm{V}}{\mathrm{W}}
$$

where $\mathrm{V}$ is the volume of aqueous $\mathrm{Cu}\left(\mathrm{NO}_{3}\right)_{2}$ solution, $\mathrm{C}_{0}$ and $\mathrm{C}_{\mathrm{R}}$ are the concentration of initial and remaining $\mathrm{Cu}\left(\mathrm{NO}_{3}\right)_{2}$, respectively; $\mathrm{W}$ is the weight of hybrid membrane.

\section{RESULTS AND DISCUSSION}

Membrane preparation: As mentioned above, the coating solution for samples A-D was obtained via sol-gel process, in which the crosslinking between the -OH groups in PVA chains and the Si-OH groups in the molecular chains of GPTMS and TMSPEDA will be performed to produce the O-Si-O linkage in the presence of acetaldehyde. In addition, the crosslinking between the $\mathrm{Si}-\mathrm{OH}$ groups in the molecular chains of GPTMS and TMSPEDA will also be occurred to create the O-Si-O linkage. The crosslinking effect of functionalized groups will increase its flexibility of hybrid precursor of sol-gel process. The membrane-type samples A-D can thus be obtained by casting the coating solution on a glass plate and underwent a subsequent desiccation steps.

TGA analysis: To gain insight into the thermal stability of samples A-D, TGA was conducted and showed in Fig. 1. Meanwhile, the thermal analysis data of samples A-D in TGA curves are analyzed and listed in Table-1.

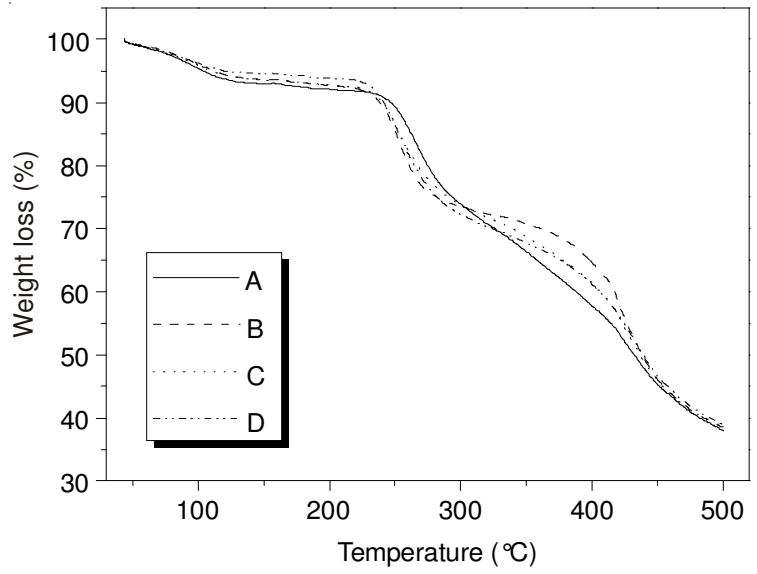

Fig. 1. TGA curves of samples A-D
TABLE-1

THERMAL ANALYSIS DATA OF SAMPLES $\mathrm{A}, \mathrm{B}, \mathrm{C}$ AND D IN TGA CURVES

\begin{tabular}{cccc}
\hline Sample & $\mathrm{T}_{\mathrm{d} 5}\left({ }^{\circ} \mathrm{C}\right)$ & $\mathrm{T}_{\mathrm{d} 10}\left({ }^{\circ} \mathrm{C}\right)$ & $\mathrm{T}_{\mathrm{d} 50}\left({ }^{\circ} \mathrm{C}\right)$ \\
\hline $\mathrm{A}$ & 104.05 & 246.95 & 431.73 \\
$\mathrm{~B}$ & 111.82 & 237.94 & 438.21 \\
$\mathrm{C}$ & 110.04 & 240.01 & 436.46 \\
$\mathrm{D}$ & 120.65 & 241.04 & 438.45 \\
\hline
\end{tabular}

From Fig. 1, it can be observed that for samples A-D, their degradation curves in weight loss (\%) are similar and three main steps are easily found. The first degradation step in weight loss (\%) from 44 to $230{ }^{\circ} \mathrm{C}$ is the evaporation of organic components and the adsorbed water. The second one in weight loss $(\%)$ can be attributed to the decomposition of functionalized groups. The three one beyond $380{ }^{\circ} \mathrm{C}$ can be assigned to the further degraded of molecular chains and the formation of hybrid matrix.

Moreover, it can also be observed that the temperature of degradation $\left(\mathrm{T}_{\mathrm{d}}\right)$ at $5,10 \%$ weight loss (i.e., $\mathrm{T}_{\mathrm{d} 5}$ and $\mathrm{T}_{\mathrm{d} 10}$ ) shows the similar change trends ( $c f$. Table-1). Meanwhile, it can be found that the weight loss $(\%)$ has a quick increase when $\mathrm{T}_{\mathrm{d}}$ value surpasses $\mathrm{T}_{\mathrm{d} 10}$, revealing that the decomposition of functionalized groups has been increased. In addition, it can be noted that the degradation temperature at $50 \%$ weight loss (i.e., $\mathrm{T}_{\mathrm{d} 50}$ ) centers at near $436{ }^{\circ} \mathrm{C}$, suggesting the formation and further perfection of hybrid matrix.

Determination of adsorption capacity: To compare adsorption efficiency of hybrid membranes for heavy-metal ions, the adsorption capacity of copper (II) on samples A-D was determined and presented in Fig. 2.

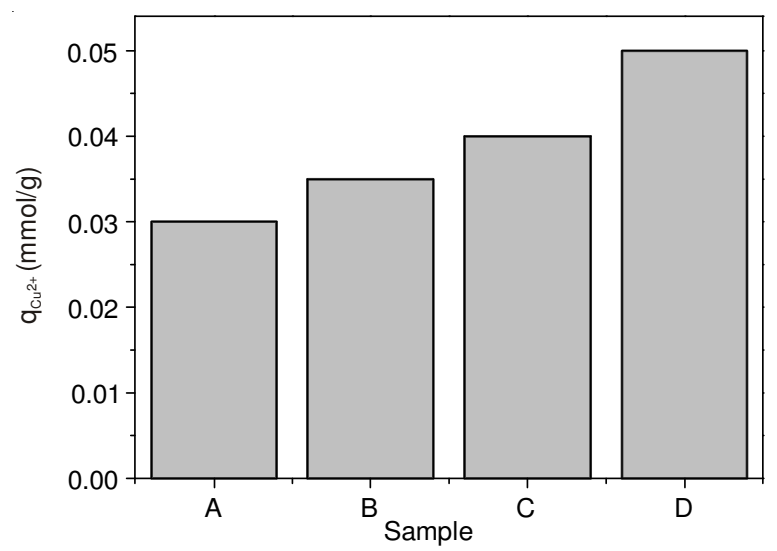

Fig. 2. Adsorption capacity of copper(II) on samples A-D. The samples were immersed in $0.01 \mathrm{~mol} / \mathrm{L}$ aqueous $\mathrm{Cu}\left(\mathrm{NO}_{3}\right)_{2}$ solution for $24 \mathrm{~h}$

From Fig. 2, it can be seen that the adsorption capacity of copper (II) on samples A-D increases from sample A to D, i.e., the adsorption capacity of copper(II) on samples A-D increases with an increase in TMSPEDA content, demonstrating that the existence of amino group in hybrid membranes will favour the adsorption of copper(II) on them. In contrast, presence of epoxy groups in these hybrid membranes doesn't support the adsorption of copper(II) on them. The reason can be assigned to the formation of complex effect between the copper and functionalized groups.

Effect of pH on copper(II) adsorption: It is well accepted that $\mathrm{pH}$ is an important factor that affects the adsorption 
behaviours of heavy-metal ions on a polymer material and high $\mathrm{pH}$ value will cause the occurrence of metal precipitate in aqueous solution. Considering such situation, the effect of $\mathrm{pH}$ on copper(II) adsorption on the above-prepared hybrid membranes was determined. Since the adsorption capacity of copper(II) on sample D has the largest value among samples A-D, only the relationship between the adsorption capacity $\left(\mathrm{q}_{\mathrm{Cu}^{2+}}\right)$ of copper(II) on sample D versus $\mathrm{pH}$ is presented in Fig. 3.

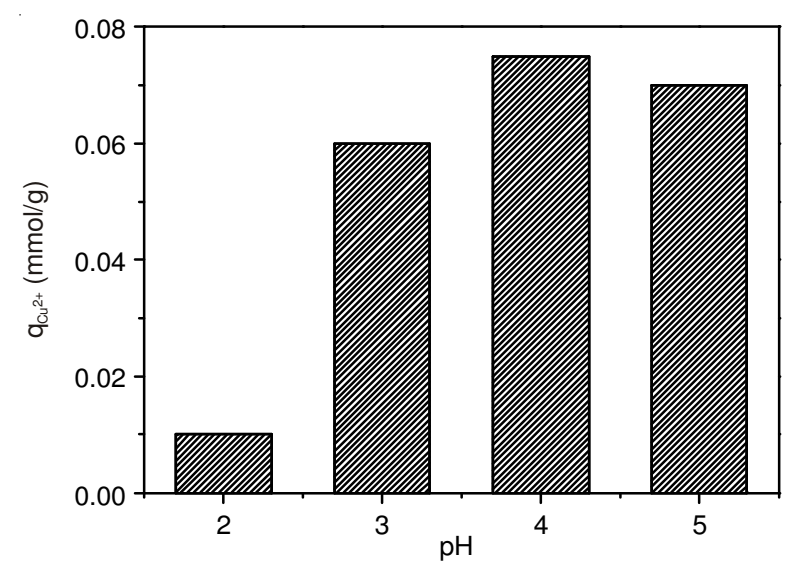

Fig. 3. $\mathrm{pH}$ versus adsorption capacity of copper(II) on sample D. The sample was immersed in $0.01 \mathrm{~mol} / \mathrm{L}$ aqueous $\mathrm{Cu}\left(\mathrm{NO}_{3}\right)_{2}$ solution for $24 \mathrm{~h}$

It can be seen that the adsorption capacity of copper(II) on sample D increases from $\mathrm{pH}$ 2-4 and then decreases from 4 to 5 , i.e., it reaches the highest value at $\mathrm{pH} 4$. Consequently, $\mathrm{pH}=4$ is more suitable for copper(II) adsorption on these hybrid membranes.

Adsorption kinetics: Fig. 4 illustrates the dependency of adsorption capacity of copper(II) on sample D on contact time $(\mathrm{t})$.

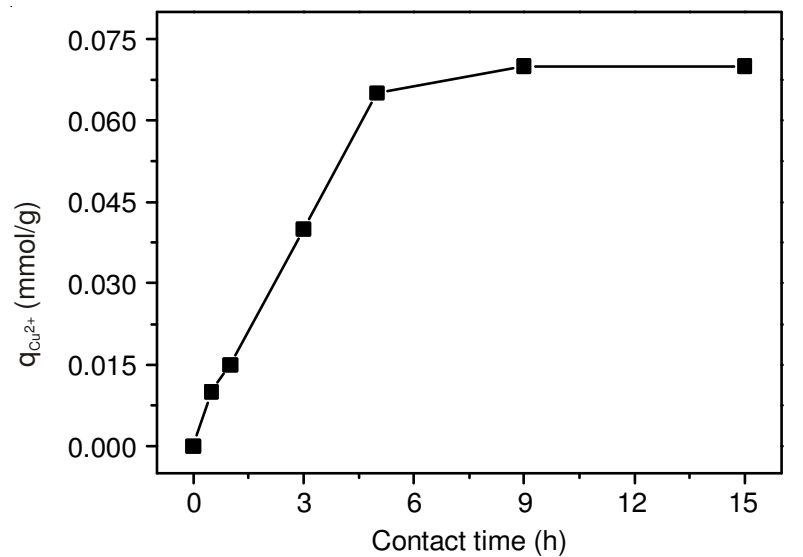

Fig. 4. Adsorption capacity of copper (II) on sample D versus contact time

From Fig. 4, it can be seen that the adsorption capacity of copper(II) on sample D increased with the elapsed contact time and reaches an equilibrium state as the contact time is higher than $6 \mathrm{~h}$.

Presently, it is well accepted that Lagergren kinetic model is a helpful tool to evaluate the adsorption performances of a material ${ }^{10-12}$. Typically, Lagergren first-order and second-order kinetic models can be linearly expressed as eqns. $2 b$ and $3 b$, respectively.

$$
\mathrm{q}_{\mathrm{t}}=\mathrm{q}_{\mathrm{e}}\left(1-\mathrm{e}^{-\mathrm{k}_{1} \mathrm{t}}\right)
$$

or

$$
\begin{gathered}
\log \left(\mathrm{q}_{\mathrm{e}}-\mathrm{q}_{\mathrm{t}}\right)=\log \mathrm{q}_{\mathrm{e}}-\frac{\mathrm{k}_{1}}{2.303} \mathrm{t} \\
\mathrm{q}_{\mathrm{t}}=\frac{\mathrm{q}_{\mathrm{e}}^{2} \mathrm{k}_{2} \mathrm{t}}{\left(1+\mathrm{q}_{\mathrm{e}} \mathrm{k}_{2} \mathrm{t}\right)} \\
\frac{\mathrm{t}}{\mathrm{q}_{\mathrm{t}}}=\frac{1}{\mathrm{k}_{2} \mathrm{q}_{\mathrm{e}}^{2}}+\frac{\mathrm{t}}{\mathrm{q}_{\mathrm{e}}}
\end{gathered}
$$

where $\mathrm{k}_{1}\left(\mathrm{~h}^{-1}\right)$ and $\mathrm{k}_{2}\left(\mathrm{~g} \mathrm{~h}^{-1} \mathrm{mmol}^{-1}\right)$ are the rate constant of first-order and second-order kinetic model, respectively; $\mathrm{q}_{\mathrm{t}}$ $\left(\mathrm{mmol} \mathrm{g}{ }^{-1}\right)$ and $\mathrm{q}_{\mathrm{e}}\left(\mathrm{mmol} \mathrm{g}^{-1}\right)$ are the adsorption capacity of metal ions $\left(\mathrm{Me}^{2+}\right)$ at time $\mathrm{t}(\mathrm{h})$ and at equilibrium state, respectively.

The Lagergren kinetic model for copper(II) adsorption on sample D was calculated and presented in Fig. 5a-b.
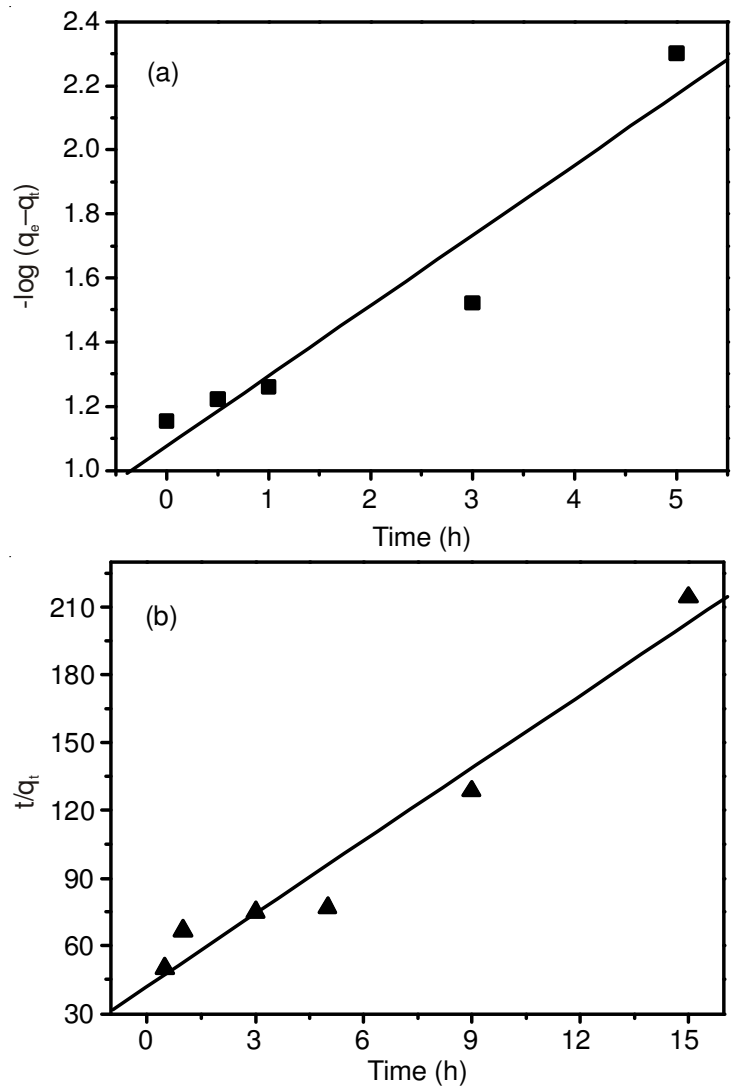

Fig. 5. Lagergren kinetic model for copper(II) adsorption on sample D, (a) first-order model, (b) second-order model

It can be seen that the linear regression coefficient $\left(\mathrm{R}^{2}\right)$ of Lagergren second-order model for copper(II) adsorption has a better fitting than that of first one (Table-2). This result suggests that copper(II) adsorption on sample D can be described using Lagergren second-order kinetic model.

\begin{tabular}{ccccccc} 
& \multicolumn{6}{c}{ TABLE-2 } \\
& \multicolumn{3}{c}{ KINETIC MODEL PARAMETERS FOR } \\
& COPPER (II) ADSORPTION ON SAMPLE D & \\
\hline \multirow{3}{*}{ Sample } & \multicolumn{3}{c}{ Lagergren first-order } & \multicolumn{3}{c}{ Lagergren second-order } \\
model & & & model & \\
\cline { 2 - 7 } & $\mathrm{k}_{1}$ & $\mathrm{q}_{\mathrm{cal}}$ & $\mathrm{R}^{2}$ & $\mathrm{k}_{2}$ & $\mathrm{q}_{\mathrm{e}}$ & $\mathrm{R}^{2}$ \\
\hline $\mathrm{D}$ & 0.504 & 0.0840 & 0.922 & 2.764 & 0.0929 & 0.958 \\
\hline
\end{tabular}




\section{Conclusion}

In this study, novel silica-based hybrid membranes were prepared and their adsorption performances were explored for the removal of copper(II) from aqueous solution It demonstrates that the adsorption of copper(II) on sample D followed the Lagergren second-order model, indicating potential application as a membrane-type hybrid adsorbent for the treatment of copper(II)-bearing water.

\section{ACKNOWLEDGEMENTS}

This project was financially supported by the National Natural Science Foundation of China (No. 21076055), the Significant Foundation of Educational Committee of Anhui Province (No. ZD2008002) and the Science and Technology Innovation Fund for Students of Hefei University (No. 11XSKY02).

\section{REFERENCES}

1. S.A. Ali, O.C.S. Al Hamouz and N.M. Hassan, J. Hazard. Mater, 248 249, 47 (2013)
2. J. Kurczewska, G. Schroeder and U. Narkiewicz, Int. J. Mater. Res., 101, 1543 (2010).

3. M.R. Awual, M. Ismael, T. Yaita, S.A.El-Safty, H. Shiwaku, Y.Okamoto and S. Suzuki, Chem. Eng. J., 222, 67 (2013).

4. J.-J. Guo and W.-B. Chen, Asian J. Chem., 25, 3609 (2013).

5. K. Xie, L. Jing, W. Zhao and Y. Zhang, J. Appl. Polym. Sci., 122, 2864 (2011).

6. K.-H. Kim, A. A. Keller and J.-K. Yang, Colloid. Surf. A, 425, 6 (2013).

7. Q. Dong, J.S. Liu, L. Song and G.Q. Shao, J. Hazard. Mater., 186, 1335 (2011).

8. X. Wang, W.X. Zhang and J.S. Liu and L.L. Wu, Asian J. Chem., 25, 6575 (2013).

9. J.S. Liu, X.H. Wang, T.W. Xu and G.Q. Shao Sep. Purif. Technol., 66, 135 (2009).

10. A. Ramesh, H. Hasegawa, T. Maki and K. Ueda, Sep. Purif. Technol., 56, 90 (2007).

11. G.P. Kumar, P.A. Kumar, S. Chakraborty and M. Ray, Sep. Purif. Technol., 57, 47 (2007).

12. A.A. Atia, A.M. Donia and A.M. Yousif, Sep. Purif. Technol., 61, 348 (2008). 